\title{
Efficacy and Cardiovascular Adverse Effects of Erythropoiesis Stimulating Agents in the Treatment of Cancer-Related Anemia: A Systematic Review of Randomized Controlled Trials
}

Sanjay Rao Gergal Gopalkrishna Rao 1, 2 , Seif Bugazia ${ }^{1,3}$, Tamil Poonkuil Mozhi Dhandapani ${ }^{4,5}$, Anjli Tara ${ }^{6,7}$, Ishan Garg 8,9 , Jaimin N. Patel ${ }^{8,10}$, Jimin Yeon ${ }^{1,11}$, Marrium S. Memon ${ }^{12}$, Abilash Muralidharan ${ }^{8,13}$, Safeera Khan ${ }^{1}$

1. Internal Medicine, California Institute of Behavioral Neurosciences \& Psychology, Fairfield, USA 2. Internal Medicine, Kasturba Medical College, Manipal, IND 3. Faculty of Medicine, University of Benghazi, Benghazi, LBY 4. Internal Medicine/Family Medicine, California Institute of Behavioral Neuroscience \& Psychology, Fairfield, USA 5. Medicine, Kanyakumari Government Medical College, Nagercoil, IND 6. General Surgery, California Institute of Behavioral Neurosciences \& Psychology, Fairfield, USA 7. General Surgery, Liaquat University of Medical and Health Sciences, Jamshoro, PAK 8. Medicine, California Institute of Behavioral Neurosciences \& Psychology, Fairfield, USA 9. Department of Medicine, Ross University School of Medicine, Miami, USA 10. Medicine, St. Martinus University Faculty of Medicine, Curacoa, CUW 11. College of Medicine, Hanyang University, Seoul, KOR 12. Research, California Institute of Behavioral Neurosciences \& Psychology, Fairfield, USA 13. Internal Medicine, State University of New York (SUNY) Downstate Health Science Center, New York, USA

Corresponding author: Sanjay Rao Gergal Gopalkrishna Rao, shakusanjay@gmail.com

Received 07/31/2021 Review began 08/25/2021 Review ended 09/03/2021 Published 09/08/2021

๑) Copyright 2021 Gergal Gopalkrishna Rao et al. This is an open access article distributed under the terms of the Creative Commons Attribution License CC-BY 4.0., which permits unrestricted use, distribution, and reproduction in any medium, provided the original author and source are credited.

\begin{abstract}
Anemia is a common complication of cancer. Treatment of anemia in cancer is crucial as anemia adversely affects the quality of life, therapeutic outcomes, and overall survival. Erythropoiesis stimulating agents (ESAs) are valuable drugs for treating cancer-related anemia. Cardiovascular adverse effects are a significant concern with ESA therapy, and there is wide variability in therapeutic goals and characteristics of patients who undergo treatment with ESAs. As a result, a careful analysis of the currently available data on the efficacy and safety of these drugs is necessary. This data analysis will aid in the rational use of ESAs for the treatment of anemia in cancer. The objective of this systematic review is to elucidate the pathogenesis of anemia in cancer, assess the effectiveness of ESAs in treating anemia in cancer, and the overall risk of cardiovascular adverse effects associated with the use of ESAs and their impact on prognosis.
\end{abstract}

We searched literature from online databases - PubMed, PubMed Central, MEDLINE, Cochrane Library, and clinical trials register (clinicaltrials.gov) to identify prospective phase II and phase III randomized controlled trials (RCTs). We chose RCTs that directly compared patients with cancer who were treated with ESAs to those who were not treated with ESAs. January 2008 was taken as the lower date limit and May 2021 as the upper date limit. Only English language literature and human studies were included. The quality appraisal was completed using the Cochrane risk bias assessment tool, and data from a total of 10,738 patients with cancer in 17 RCTs were identified and included for systematic review.

Our review concludes that ESAs effectively reduce the necessity for blood transfusions and increase mean hemoglobin levels in anemic cancer patients. ESA therapy is associated with cardiovascular adverse effects, including venous thromboembolism, thrombophlebitis, hypertension, ischemic heart disease, cardiac failure, arrhythmia, arterial thromboembolism, and cardiac arrest. Aggressive ESA dosing to achieve higher hemoglobin levels and preexisting uncontrolled hypertension increases these cardiovascular side effects. Venous thromboembolism is the most significant adverse effect attributed to ESA therapy. However, there is no major change in overall survival with ESA therapy, and administration of ESAs can be carried out in anemic cancer patients with careful assessment of thromboembolism risk factors, risk-benefit ratio, and monitoring of hemoglobin levels.

Categories: Internal Medicine, Oncology, Hematology

Keywords: erythropoiesis stimulating agents, anemia, cancer, epoetin, darbepoetin, hemoglobin, blood transfusion, thromboembolism, cardiovascular side effects

\section{Introduction And Background}

Anemia is a common complication among cancer patients. It adversely affects the quality of life and is a strong predictor of reduced survival in cancer patients [1]. The pathogenesis of anemia in cancer is multifactorial. Anemia can develop due to the underlying malignant disease, comorbidities such as nutritional deficiencies, blood loss, renal insufficiency, or as a consequence of myelosuppressive chemotherapy, radiotherapy, or a combination of all of these [2]. The type of cancer, the stage and duration 
of disease, the intensity and type of tumor therapy, and the occurrence of intercurrent infections or surgery all influence anemia in cancer [3].

Anemia affects patients with cancer in several ways. Fatigue is the most debilitating symptom. Other symptoms include impaired cognitive function, exertional dyspnea, nausea, anorexia, syncope, confusion, and depression [4]. The degree of anemia, the rapidity of its onset, and the patient's pulmonary and cardiovascular function determine the severity of the symptoms [5]. Treatment is based on the cause and the degree of anemia. The goal of therapy is to increase hemoglobin levels and correct the underlying cause [6]. The correction of anemia in cancer patients improves the quality of life, increases treatment efficacy, and has the potential to improve survival $[7,8]$.

Erythropoiesis stimulating agents (ESAs), epoetin, and darbepoetin are widely used to treat anemia in cancer. Treatment of anemia in cancer patients using ESAs significantly improves the quality of life, predominantly by reducing fatigue [9]. Although ESAs are valuable drugs for treating anemia in cancer patients, they have been reported to increase the risk of thromboembolism [10,11]. However, data on other cardiovascular adverse effects with the use of ESAs is limited. Cardiovascular adverse effects are a major concern with ESA therapy in treating anemia in cancer to impact survival. Also, therapeutic aims and characteristics of patients treated with ESAs vary greatly, necessitating a careful analysis of the currently available data on the efficacy and safety of these drugs. This data analysis helps in our ability to rationally use ESAs for the treatment of anemia in cancer.

This systematic review elucidates the pathogenesis of anemia in cancer, the effectiveness of ESAs in treating anemia in cancer, and the overall risk of cardiovascular adverse effects associated with the use of ESAs and their impact on prognosis.

\section{Review \\ Methods}

Protocol

This systematic review is in accordance with the Preferred Reporting Items for Systematic Reviews and Meta-Analyses (PRISMA) 2020 guidelines [12].

Publication Search

A methodical search of the electronic databases PubMed, PubMed Central, and MEDLINE was conducted on May 10, 2021. Keywords included in our search were "Recombinant erythropoietin," "Epoetin alfa", "Darbepoetin alfa", "Cancer," and "Anemia." For each keyword, the relevant terms of the medical subject heading $(\mathrm{MeSH})$ were identified. Each keyword was combined with its $\mathrm{MeSH}$ terms using the Boolean operator "OR" and searched in the database. Different keywords and their relevant MeSH terms were combined using the Boolean operator "AND" to get relevant studies. A total of 1635 studies were identified. We also searched Cochrane Library using the keywords and identified 66 relevant studies. Eleven relevant studies identified from the clinical trials register (clinicaltrials.gov) were also considered for review. The inclusion/exclusion criteria were applied, and randomized controlled trials (RCTs) from January 2008 to May 2021 were identified. The search was extended to studies published in the English language literature for human participants.

The Final Search Strategy

Recombinant erythropoietin OR Epoetin alfa OR Darbepoetin alfa OR ("Epoetin Alfa/administration and dosage"[Mesh] OR "Epoetin Alfa/adverse effects"[Mesh] OR "Epoetin Alfa/analogs and derivatives"[Mesh] OR "Epoetin Alfa/therapeutic use"[Mesh]) OR ("Darbepoetin alfa/administration and dosage"[Mesh] OR "Darbepoetin alfa/adverse effects"[Mesh] OR "Darbepoetin alfa/therapeutic use"[Mesh]) AND Cancer OR Malignancy OR Neoplasms OR ("Neoplasms/abnormalities"[Mesh] OR "Neoplasms/blood"[Mesh] OR "Neoplasms/complications"[Mesh] OR "Neoplasms/drug effects"[Mesh] OR "Neoplasms/drug therapy"[Mesh]) AND Anemia OR low hemoglobin OR ("Anemia/drug effects"[Mesh] OR "Anemia/drug therapy"[Mesh] OR "Anemia/therapy"[Mesh]) combinations were used.

\section{Inclusion/Exclusion Criteria}

The literature search was done to identify randomized controlled trials that directly compared patients with cancer treated with and without erythropoiesis stimulating agents (ESAs). Only English language literature and human studies were included. We chose January 2008 as the lower date limit and May 2021 as the upper date limit. Clinical trials that met the following requirements were included: Cancer patients enrolled in prospective phase II and phase III randomized controlled trials; In addition to concomitant chemotherapy and /or radiotherapy, participants with random assignment to ESA treatment or control/placebo; Available data including event or incidence of cardiovascular adverse effects and sample size for analysis. 
Following clinical trials were excluded: Phase I and single-arm phase II randomized controlled trials due to their lack of control groups; Trials with marked inequality of characteristics between groups at baseline; Trials without available data on cardiovascular adverse events.

Data Extraction

All titles, abstracts, and full-text articles were screened by two reviewers independently. The items extracted from each study included study-year, type of recombinant erythropoietin, number of patients in treatment and control/placebo group, duration of treatment, concomitant treatments, and cancer types. Data on hemoglobin response and blood transfusion requirements were extracted from the results section of each trial. Incidences of cardiovascular adverse effects were extracted from the safety profile in each trial. Another reviewer scrutinized the data extracted by the first reviewer for accuracy. Any disagreements among the reviewers were settled by consensus.

\section{Results}

Search Outcome

A total of 1701 records were identified through database searches, and 11 additional records were identified through the clinical trials register (clinicaltrials.gov). Out of 1712 records, 12 duplicates were removed. After applying inclusion/exclusion criteria, a total of 1599 records were excluded from 1700 records, including case reports, review articles, phase I studies, single-arm phase II studies, meta-analyses, observational studies, studies published before January 2008, and non-human studies. A total of 101 studies were screened. Out of 101 studies, 65 studies were excluded with reasons after careful screening of abstract, results, and safety profile. As full-text articles were unavailable, additional 12 studies were excluded, and 24 relevant studies were assessed for quality appraisal. The Cochrane Risk Bias Assessment tool was used to assess the quality appraisal of 24 studies. A total of 17 studies were selected for inclusion in the review after the quality assessment. Figure 1 demonstrates the PRISMA flow diagram and the steps taken in screening and selection of studies. 


\section{Cureus}

Identification of studies via databases and registers

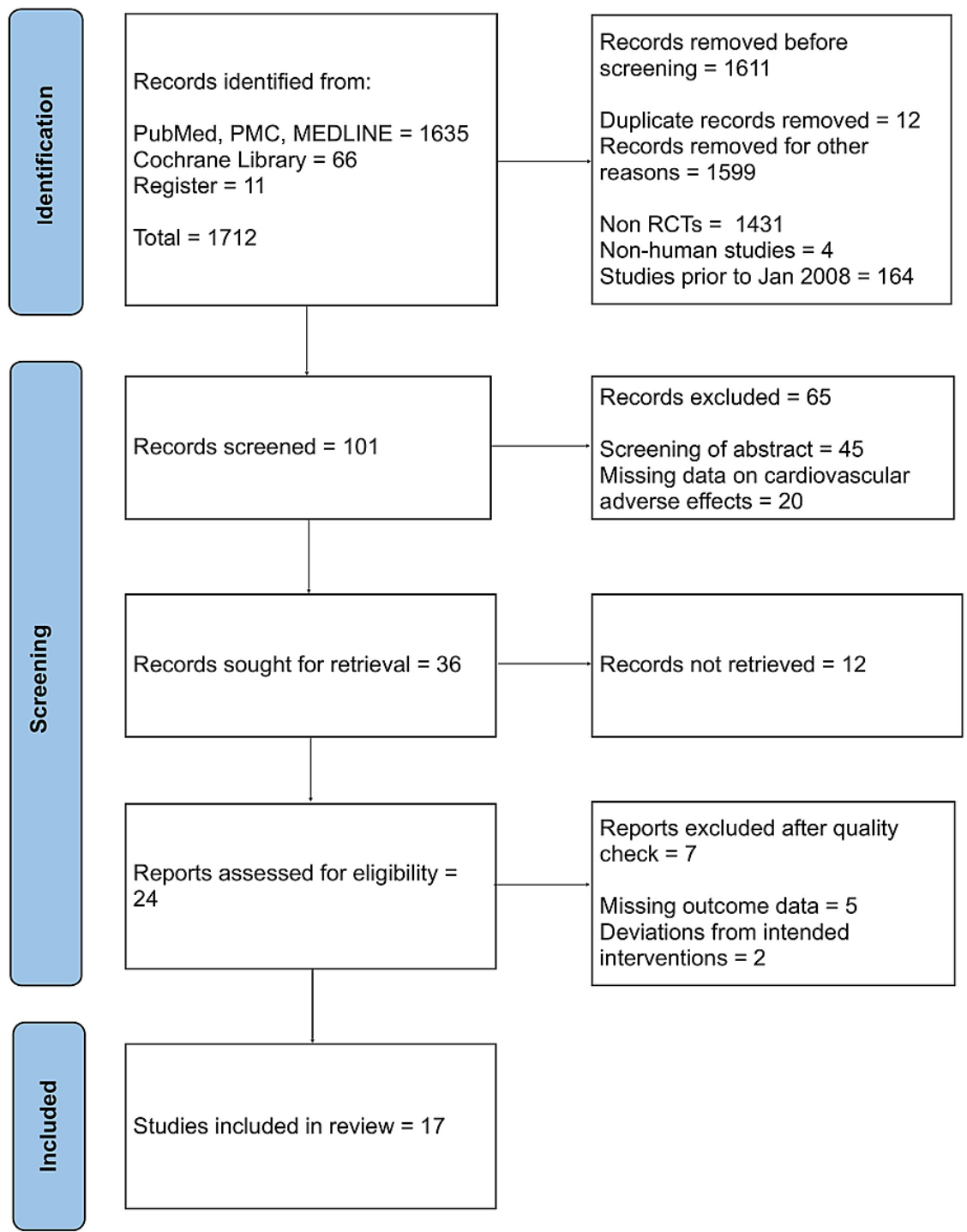

\section{FIGURE 1: PRISMA Flow Diagram}

PRISMA = Preferred Reporting Items for Systematic Reviews and Meta-Analyses; PMC = PubMed Central; RCTs $=$ Randomized Controlled Trials

Characteristics of the 17 randomized controlled trials included in the review are portrayed in Table 1 . 


\section{Cureus}

\begin{tabular}{|c|c|c|c|c|c|}
\hline Year of study & Drug & $\begin{array}{l}\text { Patients sample } \\
\text { ESA/Control }\end{array}$ & $\begin{array}{l}\text { Treatment } \\
\text { Duration }\end{array}$ & $\begin{array}{l}\text { Concomitant } \\
\text { treatment }\end{array}$ & Types of cancer \\
\hline Aapro - 2008 [13] & $\begin{array}{l}\text { Epoetin } \\
\text { beta }\end{array}$ & $463(231 / 231)$ & 24 weeks & Chemotherapy & Metastatic breast cancer \\
\hline Blohmer - 2011 [14] & Epoetin alfa & $264(128 / 129)$ & NA & Chemoradiotherapy & Cervical cancer \\
\hline Cabanillas - 2012 [15] & Epoetin alfa & $109(55 / 54)$ & NA & Chemotherapy & $\begin{array}{l}\text { ALL, lymphoblastic leukemia, } \\
\text { Burkitt lymphoma }\end{array}$ \\
\hline Engert - $2010[16]$ & Epoetin alfa & $1303(648 / 655)$ & NA & Chemotherapy & $\begin{array}{l}\text { Advanced stage Hodkin's } \\
\text { lymphoma }\end{array}$ \\
\hline Fujisaka - 2011 [17] & $\begin{array}{l}\text { Epoetin } \\
\text { beta }\end{array}$ & $181(89 / 92)$ & 12 weeks & Chemotherapy & Lung or gynecological cancer \\
\hline Gascon - 2019 [18] & $\begin{array}{l}\text { Darbepoetin } \\
\text { alfa }\end{array}$ & $2516(1680 / 836)$ & NA & Chemotherapy & Stage IV NSCLC \\
\hline Gupta - 2009 [19] & $\begin{array}{l}\text { Epoetin } \\
\text { beta }\end{array}$ & $115(58 / 57)$ & Five weeks & Chemoradiotherapy & Advanced cervical cancer \\
\hline Hernandez - 2009 [20] & $\begin{array}{l}\text { Darbepoetin } \\
\text { alfa }\end{array}$ & $386(194 / 192)$ & 16 weeks & Chemotherapy & $\begin{array}{l}\text { Lung, ovarian, cervical, breast, } \\
\text { and others }\end{array}$ \\
\hline Hoskin - 2009 [21] & Epoetin alfa & $300(151 / 149)$ & NA & Radiotherapy & Head and neck cancer \\
\hline $\begin{array}{l}\text { Leyland - Jones - } 2016 \\
\text { [22] }\end{array}$ & Epoetin alfa & 2098 (1050/1048) & NA & Chemotherapy & Metastatic breast cancer \\
\hline Pirker - 2008 [23] & $\begin{array}{l}\text { Darbepoetin } \\
\text { alfa }\end{array}$ & $600(301 / 299)$ & Nine weeks & Chemotherapy & Extensive stage SCLC \\
\hline Platzbecker - 2017 [24] & $\begin{array}{l}\text { Darbepoetin } \\
\text { alfa }\end{array}$ & $146(97 / 49)$ & 24 weeks & Chemotherapy & Myelodysplastic syndromes \\
\hline Pronzato - 2010 [25] & Epoetin alfa & $216(107 / 109)$ & Four weeks & Chemotherapy & Breast cancer \\
\hline $\begin{array}{l}\text { Ray Coquard - } 2009 \\
\text { [26] }\end{array}$ & Epoetin alfa & $218(110 / 108)$ & 12 weeks & Chemotherapy & Non-Hodgkin's lymphoma \\
\hline Smith Jr - 2008 [27] & $\begin{array}{l}\text { Darbepoetin } \\
\text { alfa }\end{array}$ & $989(517 / 472)$ & 16 weeks & $\begin{array}{l}\text { No chemotherapy or } \\
\text { radiotherapy }\end{array}$ & Non-myeloid malignancy \\
\hline Tsuboi - 2009 [28] & $\begin{array}{l}\text { Epoetin } \\
\text { beta }\end{array}$ & $120(62 / 58)$ & Eight weeks & Chemotherapy & $\begin{array}{l}\text { Lung cancer or malignant } \\
\text { lymphoma }\end{array}$ \\
\hline Untch - 2011 [29] & $\begin{array}{l}\text { Darbepoetin } \\
\text { alfa }\end{array}$ & $714(396 / 318)$ & NA & Chemotherapy & Primary breast cancer \\
\hline To & & 10, & & & \\
\hline
\end{tabular}

\section{TABLE 1: Characteristics of randomized controlled trials included in the review}

$\mathrm{ESA}=$ Erythropoiesis stimulating agent; $\mathrm{ALL}=$ Acute lymphocytic leukemia; $\mathrm{NSCLC}=$ Non-small cell lung cancer; $\mathrm{SCLC}=\mathrm{Small}$ cell lung cancer

Epoetin alfa or epoetin beta was evaluated in 11 trials with 5,387 patients and darbepoetin alfa in six trials with 5,351 patients. Concomitant treatment varied between trials as follows: chemotherapy (13 trials), radiotherapy (one trial), chemoradiotherapy (two trials), and no treatment (one trial). Eleven trials included 8,807 patients with a single cancer diagnosis [lung cancer (two trials), breast cancer (four trials), head and neck cancer (one trial), cervical cancer (two trials), and non-Hodgkin's lymphoma (two trials)].

\section{Discussion}

Pathogenesis of Anemia in Cancer

The pathogenesis of anemia in cancer is multifactorial. Anemia can be caused by chronic inflammation and the synthesis of pro-inflammatory cytokines by both immune and cancer cells [30]. Chronic inflammation 
leads to suppression of erythropoiesis in bone marrow, shortened erythrocyte survival, increased erythrocyte destruction, changes in iron metabolism due to an increase in hepcidin, and iron-restricted erythropoiesis [31]. Pro-inflammatory cytokines in cancer cause macrophage activation and increased destruction of erythrocytes. Iron restriction and the direct inhibitory action of cytokines on erythropoietic progenitors leads to suppression of erythropoiesis. A direct effect of pro-inflammatory cytokines [interleukin (IL)-1, IL6, tumor necrosis factor (TNF)-alpha] on kidney cells that produce erythropoietin can cause impairment of erythropoietin synthesis [32], and erythropoietin levels are inadequately low for hemoglobin levels in cancer [33]. The cytokine IL-6 induces hepatic synthesis of hepcidin, which regulates iron homeostasis by controlling the degradation of the iron export protein ferroportin-1, which prevents iron absorption from the small intestine and release of iron from macrophages. Iron is therefore unavailable for erythropoiesis [34]. In addition to cytokine production, cancer itself can cause anemia by suppressing hematopoiesis through bone marrow infiltration. Poor nutritional status is another factor that contributes to anemia in cancer. Patients with advanced cancer often have nausea, vomiting, loss of appetite, and deficiencies of iron, vitamin B12, and folate essential for erythropoiesis. Blood loss associated with cancer surgery or bleeding within the tumor causes anemia [35]. Also, antineoplastic therapies (chemotherapy and radiotherapy) can lead to anemia. Radiation therapy leads to anemia by causing damage to the bone marrow.

Chemotherapeutic agents induce anemia by impairing hematopoiesis. Some chemotherapeutic agents are toxic to bone marrow, while others are nephrotoxic, which leads to reduced erythropoietin production by the kidney [36].

\section{Effectiveness of ESA Therapy: Reduction in Blood Transfusion}

Acute or chronic anemia is often associated with the development of tumor hypoxia. In this condition, tumor cells in the hypoxic areas of solid tumors are resistant to conventional chemotherapy and radiotherapy [37]. Tumour hypoxia adversely impacts radiotherapy or combined radiotherapy-chemotherapy outcomes and chronic hypoxia, caused by anemia, decreases the efficacy of chemotherapy and radiotherapy [38]. Therefore, prevention and treatment of anemia in cancer is a major goal in managing cancer patients.

Anemia in cancer is primarily treated with packed red blood cell (PRBC) transfusion or administration of erythropoiesis-stimulating agents (ESAs). Hemoglobin and hematocrit levels increase quickly after a packed red blood cell transfusion. However, transfusion carries the risk of transfusion-related reactions, congestive heart failure, bacterial contamination, viral infections, and iron overload [39]. In this review, by reference to several clinical trials, we evaluated the incidence of blood transfusions in patients receiving ESAs and patients not receiving ESAs. Out of 17 randomized controlled trials included in this review, 14 trials compared the proportion of participants who received blood transfusions in the ESA group with the control group. Among the 14 trials, 13 trials showed that the number of participants who received at least one blood transfusion was lesser in the ESA group compared with the control group. In one trial, Cabanillas et al. showed no significant difference in the number of PRBC transfusion events per week between the two treatment groups $(\mathrm{P}=.089)[15]$. However, the total number of blood transfusions administered per week was lesser in the ESA group compared with the control. The results of the trials are presented in Table 2. 


\section{Cureus}

\begin{tabular}{|c|c|c|c|c|}
\hline Study & ESA & $\begin{array}{l}\text { Proportion of participants } \\
\text { who received transfusion in } \\
\text { ESA group }\end{array}$ & $\begin{array}{l}\text { Proportion of participants who } \\
\text { received transfusion in } \\
\text { Control group }\end{array}$ & $P$ value \\
\hline $\begin{array}{l}\text { Aapro - } \\
2008 \text { [13] }\end{array}$ & Epoetin beta & $14 \%$ & $27 \%$ & $<0.001$ \\
\hline $\begin{array}{l}\text { Blohmer - } \\
2011 \text { [14] }\end{array}$ & Epoetin alfa & $10.7 \%$ & $29.6 \%$ & $<0.001$ \\
\hline $\begin{array}{l}\text { Cabanillas - } \\
2012 \text { [15] }\end{array}$ & Epoetin alfa & No difference & No difference & $\begin{array}{l}\text { Number of PRBC units transfused } \\
\text { per week } 10.63 \pm 6.29 \text { vs. } 13.11 \pm \\
5.18 ; p<0.035\end{array}$ \\
\hline $\begin{array}{l}\text { Engert - } \\
2010[16]\end{array}$ & Epoetin alfa & $63.3 \%$ & $72.6 \%$ & $<0.001$ \\
\hline $\begin{array}{l}\text { Fujisaka - } \\
2011 \text { [17] }\end{array}$ & Epoetin beta & $4.5 \%$ & $19.6 \%$ & $=0.002$ \\
\hline $\begin{array}{l}\text { Gascon - } \\
2019 \text { [18] }\end{array}$ & $\begin{array}{l}\text { Darbepoeitin } \\
\text { alfa }\end{array}$ & $23.4 \%$ & $29.1 \%$ & $=0.01$ \\
\hline $\begin{array}{l}\text { Gupta - } \\
2009 \text { [19] }\end{array}$ & Epoetin beta & $15.5 \%$ & $43.8 \%$ & $<0.01$ \\
\hline $\begin{array}{l}\text { Hernandez - } \\
2009 \text { [20] }\end{array}$ & $\begin{array}{l}\text { Darbepoeitin } \\
\text { alfa }\end{array}$ & $24 \%$ & $41 \%$ & $<0.001$ \\
\hline $\begin{array}{l}\text { Leyland- } \\
\text { Jones - } \\
2016 \text { [22] }\end{array}$ & Epoetin alfa & $5.8 \%$ & $11.4 \%$ & $<0.001$ \\
\hline $\begin{array}{l}\text { Pirker - } 2008 \\
\text { [23] }\end{array}$ & $\begin{array}{l}\text { Darbepoeitin } \\
\text { alfa }\end{array}$ & $17 \%$ & $39 \%$ & $<0.001$ \\
\hline $\begin{array}{l}\text { Platzbecker } \\
\text { - } 2017 \text { [24] }\end{array}$ & $\begin{array}{l}\text { Darbepoeitin } \\
\text { alfa }\end{array}$ & $36.1 \%$ & $59.2 \%$ & $=0.008$ \\
\hline $\begin{array}{l}\text { Pronzato - } \\
2010 \text { [25] }\end{array}$ & Epoetin alfa & $3 \%$ & $10.1 \%$ & $=0.048$ \\
\hline $\begin{array}{l}\text { Ray- } \\
\text { Coquard - } \\
2009 \text { [26] }\end{array}$ & Epoetin alfa & $36.1 \%$ & $58.1 \%$ & $=0.001$ \\
\hline $\begin{array}{l}\text { Tsuboi - } \\
2009 \text { [28] }\end{array}$ & Epoetin beta & $16.4 \%$ (after four weeks) & $32.1 \%$ (after 4 weeks) & $=0.046$ \\
\hline
\end{tabular}

\section{TABLE 2: Proportion of participants who received a blood transfusion in ESA group vs Control}

group

ESA $=$ Erythropoiesis stimulating agent; $\mathrm{PRBC}=$ Packed red blood cell

The studies showed that ESAs are valuable drugs in treating anemia in cancer as they improve clinical outcomes significantly by reducing the need for blood transfusions in cancer patients.

Effectiveness of ESA Therapy: Mean Change in Hemoglobin Levels

A rise in hemoglobin levels in anemic cancer patients can improve physical and emotional well-being. An increase in energy levels, decreased fatigue, improved therapeutic outcomes, and reduced need for blood transfusions with an increase in hemoglobin levels lead to improved quality of life. The change in mean hemoglobin level from the baseline was compared between the ESA group and the control group in 10 trials. Out of 10 trials, eight trials showed a greater mean hemoglobin level in the ESA group than in the control group. In one trial, Cabanillas et al. showed no difference between the groups [15]. In another trial, Pirker et al. showed decreased mean hemoglobin levels in both groups [23]. However, the drop in hemoglobin level was less in the ESA group compared with the control group. The results of the trials are presented in Table 3. 


\section{Cureus}

\begin{tabular}{|c|c|c|c|c|}
\hline Study & ESA & $\begin{array}{l}\text { Mean change in } \mathrm{Hb} \text { level in ESA } \\
\text { group }\end{array}$ & $\begin{array}{l}\text { Mean change in } \mathrm{Hb} \text { level in Control } \\
\text { group }\end{array}$ & $P$ value \\
\hline Aapro - 2008 [13] & Epoetin beta & $1.5 \mathrm{~g} / \mathrm{dl}$ & $-0.1 \mathrm{~g} / \mathrm{dl}$ & $<0.05$ \\
\hline Cabanillas - 2012 [15] & Epoetin alfa & No difference & No difference & $<0.21$ \\
\hline Fujisaka - 2011 [17] & Epoetin beta & $1.9 \mathrm{~g} / \mathrm{dl}$ & $0.0 \mathrm{~g} / \mathrm{dl}$ & $<0.001$ \\
\hline Gascon - 2019 [18] & $\begin{array}{l}\text { Darbepoeitin } \\
\text { alfa }\end{array}$ & $0.42 \mathrm{~g} / \mathrm{dl}$ & $-0.12 \mathrm{~g} / \mathrm{dl}$ & $<0.05$ \\
\hline Gupta - 2009 [19] & Epoetin beta & $1.55 \mathrm{~g} / \mathrm{dl}$ & $-1.50 \mathrm{~g} / \mathrm{dl}$ & $<0.01$ \\
\hline $\begin{array}{l}\text { Leyland- Jones - } 2016 \\
\text { [22] }\end{array}$ & Epoetin alfa & $11.6(10.4) \mathrm{g} / \mathrm{dl}$ & 10.9 (10.5) g/dl & $<0.05$ \\
\hline Pirker - 2008 [23] & $\begin{array}{l}\text { Darbepoeitin } \\
\text { alfa }\end{array}$ & $-1.13 \mathrm{~g} / \mathrm{dl}$ & $-1.98 \mathrm{~g} / \mathrm{dl}$ & $<0.001$ \\
\hline Pronzato - 2010 [25] & Epoetin alfa & $10.6 \mathrm{~g} / \mathrm{dll}$ to $12.3 \mathrm{~g} / \mathrm{dl}$ & $10.8 \mathrm{~g} / \mathrm{dll}$ to $11.2 \mathrm{~g} / \mathrm{dl}$ & $<0.001$ \\
\hline Smith Jr - 2008 [27] & $\begin{array}{l}\text { Darbepoeitin } \\
\text { alfa }\end{array}$ & $0.73 \mathrm{~g} / \mathrm{dl}$ & $0.29 \mathrm{~g} / \mathrm{dl}$ & $<0.0001$ \\
\hline Tsuboi - 2009 [28] & Epoetin beta & $1.4 \pm 1.9 \mathrm{~g} / \mathrm{dl}$ & $-0.8 \pm 1.5 \mathrm{~g} / \mathrm{dl}$ & $<0.001$ \\
\hline
\end{tabular}

\section{TABLE 3: Mean change in $\mathrm{Hb}$ level in ESA group vs Control group}

$\mathrm{Hb}=$ Hemoglobin; ESA = Erythropoiesis stimulating agent

Five trials also compared the proportion of patients with an increase in hemoglobin level between the ESA and the control group. All five trials showed that the proportion of patients with an increase in hemoglobin level was higher in the ESA group compared with the control group. The results are presented in Table 4.

\begin{tabular}{|l|l|l|l|l|}
\hline Study & ESA & $\begin{array}{l}\text { Percentage of patients with an } \\
\text { increase in mean Hb level in ESA } \\
\text { group }\end{array}$ & $\begin{array}{l}\text { Percentage of patients with an increase } \\
\text { in mean Hb level in the control group }\end{array}$ & $\begin{array}{l}\text { P } \\
\text { value }\end{array}$ \\
\hline $\begin{array}{l}\text { Aapro }-2008[13] \\
\text { Blohmer }-2011\end{array}$ & Epoetin beta & $68 \%$ & $14 \%$ & $<0.001$ \\
\hline$[14]$ & Epoetin alfa & $51 \%$ & $14 \%$ & $<0.001$ \\
\hline $\begin{array}{l}\text { Platzbecker }-2017 \\
{[24]}\end{array}$ & Darbepoetin alfa & $14.7 \%$ & $0 \%$ & $=0.016$ \\
\hline $\begin{array}{l}\text { Pronzato }-2010 \\
{[25]}\end{array}$ & Epoeitin alfa & $62 \%$ & $28 \%$, & $<0.01$ \\
\hline $\begin{array}{l}\text { Tsuboi }-2009[28] \\
\text { Epoetin beta }\end{array}$ & $42.6 \%$ & $1.8 \%$ & $<0.001$ \\
\hline
\end{tabular}

\section{TABLE 4: Percentage of patients with an increase in mean $\mathrm{Hb}$ level in ESA group vs Control} group

$\mathrm{Hb}=$ Hemoglobin; ESA = Erythropoiesis stimulating agent

The studies showed ESAs are effective in raising mean hemoglobin levels in anemic cancer patients.

ESA Therapy: Cardiovascular Adverse Effects

ESA therapy is generally well tolerated. However, as with any other drug therapy, ESAs are associated with side effects. Cardiovascular side effects are a major concern with ESA therapy. In this present review, by 
reference to several clinical trials, we outlined the cardiovascular risks of ESAs in the treatment of cancerrelated anemia. We involved 17 randomized controlled trials, including 5797 cancer patients with ESA and 4930 patients with controls. Cardiovascular side effects were observed in 16 trials in both the ESA group and the control group. In only one trial reported by Gupta et al., there were no cardiovascular side effects in either group [19]. The side effects observed were more in the ESA group than the control group in 14 trials. In two trials, Blohmer et al. [14] and Platzbecker et al. [24], cardiovascular side effects were comparable between two groups. Six-hundred seventy-seven patients out of 5797 patients in the ESA group experienced cardiovascular side effects compared to 418 patients out of 4930 patients in the control group. The type of side effects included venous thromboembolism, thrombophlebitis, hypertension, ischemic heart disease, cardiac failure, arrhythmia, arterial thromboembolism, and cardiac arrest. Venous thromboembolism is the most significant cardiovascular adverse effect attributed to ESA therapy as all the 16 trials had at least one event. A total of 286 patients experienced venous thromboembolism with ESAs compared to 170 patients with control. In all the 16 trials with cardiovascular side effects, venous thromboembolism events were greater in the ESA group compared to the control group. Overall survival between the ESA and control groups was compared in the 16 trials with cardiovascular side effects. Fifteen trials showed no significant difference in overall survival between the two groups. Only one trial, reported by Smith Jr et al., showed statistically significantly poorer survival in patients treated with darbepoetin versus placebo $(\mathrm{P}=.022)$ [27]. The cardiovascular side effects in ESA and control groups are presented in Table 5.

\begin{tabular}{|c|c|c|c|c|c|}
\hline Study & $\begin{array}{l}\text { Participants with } \\
\text { cardiovascular side } \\
\text { effects in the ESA } \\
\text { group }\end{array}$ & $\begin{array}{l}\text { participants } \\
\text { in the ESA } \\
\text { group }\end{array}$ & $\begin{array}{l}\text { cardiovascular side } \\
\text { effects in the } \\
\text { control group }\end{array}$ & $\begin{array}{l}\text { Total } \\
\text { participants } \\
\text { in the } \\
\text { control } \\
\text { group }\end{array}$ & Type of cardiovascular side effects \\
\hline $\begin{array}{l}\text { Aapro - } \\
2008[13]\end{array}$ & 29 & 231 & 13 & 231 & $\begin{array}{l}\text { Pulmonary embolism, Thrombophlebitis, } \\
\text { Deep venous thrombosis }\end{array}$ \\
\hline $\begin{array}{l}\text { Blohmer - } \\
2011[14]\end{array}$ & 2 & 128 & 3 & 129 & $\begin{array}{l}\text { Pulmonary embolism, Deep venous } \\
\text { thrombosis }\end{array}$ \\
\hline $\begin{array}{l}\text { Cabanillas - } \\
2012[15]\end{array}$ & b & 50 & 2 & 34 & Ihrombotic events \\
\hline $\begin{array}{l}\text { Engert - } \\
2010[16]\end{array}$ & 6 & 048 & 3 & 050 & vascular aisoraers \\
\hline $\begin{array}{l}\text { Fujısaka - } \\
2011[17]\end{array}$ & b & 89 & 3 & 92 & Hypertensıon, Pulmonary embolısm \\
\hline $\begin{array}{l}\text { Gascon - } \\
2019[18]\end{array}$ & 261 & 1680 & 115 & 836 & $\begin{array}{l}\text { Thromboembolism, Hypertension, } \\
\text { Ischemic heart disease, Cardiac failure }\end{array}$ \\
\hline $\begin{array}{l}\text { Gupta - } \\
2009[19]\end{array}$ & 0 & 58 & 0 & 36 & NA \\
\hline $\begin{array}{l}\text { Hernandez } \\
-2009[20]\end{array}$ & 42 & 194 & 32 & 192 & $\begin{array}{l}\text { Arrhythmia, Cardiac failure, Hypertension, } \\
\text { Ischemic heart disease, Thromboembolism, } \\
\text { Cardiac arrest, Vascular disorders }\end{array}$ \\
\hline $\begin{array}{l}\text { Hoskın - } \\
2009[21]\end{array}$ & 8 & 151 & r & 149 & $\begin{array}{l}\text { Hypertension, Chest pain, Coronary artery } \\
\text { disorder, Cardiac arrest, Thromboembolism }\end{array}$ \\
\hline $\begin{array}{l}\text { Leyland - } \\
\text { Jones - } \\
2016 \text { [22] }\end{array}$ & 29 & 1050 & 15 & 1048 & $\begin{array}{l}\text { Arterial thrombosis/embolism, Venous } \\
\text { thrombosis/embolism, Acute coronary } \\
\text { syndrome, Pulmonary embolism }\end{array}$ \\
\hline $\begin{array}{l}\text { PIrker - } \\
2008 \text { [23] }\end{array}$ & 140 & 301 & 101 & 296 & $\begin{array}{l}\text { Thromboembolism, Arrhythmia, Heart } \\
\text { failure, Coronary artery disorder, } \\
\text { Thrombosis (arterial and venous), } \\
\text { Hypertension }\end{array}$ \\
\hline - 2017 [24] & 7 & 98 & 8 & 48 & $\begin{array}{l}\text { Hypertension, Heart failure, Ischemic heart } \\
\text { disease, Thromboembolism (venous and } \\
\text { arterial) }\end{array}$ \\
\hline $\begin{array}{l}\text { Pronzato - } \\
2010[25]\end{array}$ & 8 & 107 & r & 109 & Inrombovascular event \\
\hline
\end{tabular}




\section{Cureus}

\begin{tabular}{|llllll|}
$\begin{array}{l}\text { Coquard - } \\
2009[26]\end{array}$ & 5 & 110 & 4 & 108 & Thrombovascular event \\
$\begin{array}{l}\text { Smith Jr - } \\
2008[27]\end{array}$ & 106 & 517 & 87 & 472 & $\begin{array}{l}\text { Thromboembolic event, Arterial and venous } \\
\text { thrombosis/embolism, Arrhythmia, Heart } \\
\text { failure, Coronary artery disorders, } \\
\text { Hypertension }\end{array}$ \\
$\begin{array}{l}\text { Tsuboi - } \\
2009[28]\end{array}$ & 5 & 62 & 4 & 58 & Thrombovascular event, Hypertension \\
$\begin{array}{l}\text { Untch - } \\
2011[29]\end{array}$ & 18 & 318 & 12 & 396 & Thromboembolism \\
Total & 677 & 5797 & 418 & 4930 & - \\
\hline
\end{tabular}

\section{TABLE 5: Cardiovascular side effects in ESA group vs Control group}

ESA = Erythropoiesis stimulating agent

The studies showed ESA therapy is associated with cardiovascular side effects, including venous thromboembolism, thrombophlebitis, hypertension, ischemic heart disease, cardiac failure, arrhythmia, arterial thromboembolism, and cardiac arrest. An increase in these side effects was noted with aggressive ESA dosing to obtain higher hemoglobin levels, and in patients with preexisting uncontrolled hypertension. Venous thromboembolism is the most significant cardiovascular side effect attributed to ESA therapy, as it was found consistently in all the trials (16/16). The risk of thrombosis was higher in patients with preexisting ischemic heart disease and congestive heart failure and lower in young patients and patients with previous thromboembolic events who received anticoagulation prophylaxis. However, these side effects did not significantly impact overall survival as 15 out of 16 trials showed no change in overall survival between the ESA group and the control group.

Limitations

Our review has the following limitations. As this is a review at the study level, patient-level confounding factors could not be appropriately assessed and incorporated into the analysis. Some of the studies did not specify criteria for administering blood transfusions, which could impact ESA dosage and therapy. The association between the risk for cardiovascular adverse effects and the duration of ESA therapy could not be determined with the available data. The study did not distinguish incidental findings of cardiovascular adverse events, contributing to a bias of the reported incidence rates. Since we have taken the lower limit date as January 2008, we have not included the RCTs published before January 2008 that might be relevant to this analysis.

\section{Conclusions}

Erythropoiesis stimulating agents (ESAs) are effective and valuable drugs in the treatment of anemia in cancer patients. ESAs improve clinical outcomes significantly by reducing the need for blood transfusions in cancer patients. ESAs are effective in increasing mean hemoglobin levels. However, ESA therapy is associated with cardiovascular adverse effects, including venous thromboembolism, thrombophlebitis, hypertension, ischemic heart disease, cardiac failure, arrhythmia, arterial thromboembolism, and cardiac arrest. These side effects are higher in patients with preexisting uncontrolled hypertension and with aggressive ESA dosing to achieve higher hemoglobin levels. Venous thromboembolism is the most significant cardiovascular adverse effect associated with the use of ESAs, but ESA therapy does not have a discernible role in overall survival. The risk-benefit ratio of ESA treatment in cancer-related anemia should be assessed carefully for each cancer patient. Caution is advised when using epoetin or darbepoetin in combination with thrombogenic chemotherapeutic agents or for cancer patients at high risk for thromboembolic events. The cellular and molecular processes and pathways by which ESAs affect thrombogenesis are not distinct. More research is needed on this subject. Elucidation of the role of ESAs in thrombosis will improve our ability to use ESAs rationally in the clinical setting and helps in the prevention and management of thromboembolism. Concerning potential risks and benefits, ESA therapy can be carried out in anemic cancer patients with careful assessment of thromboembolism risk factors and monitoring of hemoglobin levels.

\section{Additional Information}

\section{Disclosures}

Conflicts of interest: In compliance with the ICMJE uniform disclosure form, all authors declare the 
following: Payment/services info: All authors have declared that no financial support was received from any organization for the submitted work. Financial relationships: All authors have declared that they have no financial relationships at present or within the previous three years with any organizations that might have an interest in the submitted work. Other relationships: All authors have declared that there are no other relationships or activities that could appear to have influenced the submitted work.

\section{References}

1. Caro JJ, Salas M, Ward A, Goss G: Anemia as an independent prognostic factor for survival in patients with cancer: a systemic, quantitative review. Cancer. 2001, 91:2214-21. 10.1002/10970142(20010615)91:12<2214::AID-CNCR1251>3.0.CO;2-P

2. Steensma DP: Is anemia of cancer different from chemotherapy-induced anemia? . J Clin Oncol. 2008, 26:1022-4. 10.1200/JCO.2007.15.3874

3. Mercadante S, Gebbia V, Marrazzo A, Filosto S: Anaemia in cancer: pathophysiology and treatment. Cancer Treat Rev. 2000, 26:303-11. 10.1053/ctrv.2000.0181

4. Cella D: Factors influencing quality of life in cancer patients: anemia and fatigue . Semin Oncol. 1998, 25:43-6.

5. Yellen SB, Cella DF, Webster K, Blendowski C, Kaplan E: Measuring fatigue and other anemia-related symptoms with the Functional Assessment of Cancer Therapy (FACT) measurement system. J Pain Symptom Manage. 1997, 13:63-74. 10.1016/s0885-3924(96)00274-6

6. Low blood cell counts (Anemia). (2020). Accessed: May 24, 2021: https://www.cancer.org/treatment/treatments-and-side-effects/physical-side-effects/low-bloodcounts/anemia.html.

7. Glaspy J, Degos L, Dicato M, Demetri GD: Comparable efficacy of epoetin alfa for anemic cancer patients receiving platinum- and nonplatinum-based chemotherapy: a retrospective subanalysis of two large, community-based trials. Oncologist. 2002, 7:126-35. 10.1634/theoncologist.7-2-126

8. Calabrich A, Katz A: Management of anemia in cancer patients . Future Oncol. 2011, 7:507-17. 10.2217/fon.11.24

9. Minton O, Richardson A, Sharpe M, Hotopf M, Stone P: A systematic review and meta-analysis of the pharmacological treatment of cancer-related fatigue. J Natl Cancer Inst. 2008, 100:1155-66. 10.1093/jnci/djn250

10. Bohlius J, Wilson J, Seidenfeld J, et al.: Recombinant human erythropoietins and cancer patients: updated meta-analysis of 57 studies including 9353 patients. J Natl Cancer Inst. 2006, 98:708-14. 10.1093/jnci/djj189

11. Bennett CL, Silver SM, Djulbegovic B, et al.: Venous thromboembolism and mortality associated with recombinant erythropoietin and darbepoetin administration for the treatment of cancer-associated anemia. JAMA. 2008, 299:914-24. 10.1001/jama.299.8.914

12. Page MJ, McKenzie JE, Bossuyt PM, et al.: The PRISMA 2020 statement: an updated guideline for reporting systematic reviews. BMJ. 2021, 372:n71. 10.1136/bmj.n71

13. Aapro M, Leonard RC, Barnadas A, et al.: Effect of once-weekly epoetin beta on survival in patients with metastatic breast cancer receiving anthracycline- and/or taxane-based chemotherapy: results of the breast cancer-anemia and the value of erythropoietin (BRAVE) study. J Clin Oncol. 2008, 26:592-8. 10.1200/JCO.2007.11.5378

14. Blohmer JU, Paepke S, Sehouli J, et al.: Randomized phase III trial of sequential adjuvant chemoradiotherapy with or without erythropoietin Alfa in patients with high-risk cervical cancer: results of the NOGGO-AGO intergroup study. J Clin Oncol. 2011, 29:3791-7. 10.1200/JCO.2010.30.4899

15. Cabanillas ME, Kantarjian H, Thomas DA, et al.: Epoetin alpha decreases the number of erythrocyte transfusions in patients with acute lymphoblastic leukemia, lymphoblastic lymphoma, and Burkitt leukemia/lymphoma: results of a randomized clinical trial. Cancer. 2012, 118:848-55. 10.1002/cncr.26341

16. Engert A, Josting A, Haverkamp H, et al.: Epoetin alfa in patients with advanced-stage Hodgkin's lymphoma: results of the randomized placebo-controlled GHSG HD15EPO trial. J Clin Oncol. 2010, 28:2239-45. 10.1200/JCO.2009.25.1835

17. Fujisaka Y, Sugiyama T, Saito H, et al.: Randomised, phase III trial of epoetin- $\beta$ to treat chemotherapyinduced anaemia according to the EU regulation. Br J Cancer. 2011, 105:1267-72. 10.1038/bjc.2011.395

18. Gascón P, Nagarkar R, Šmakal M, et al.: A randomized, double-blind, placebo-controlled, phase III noninferiority study of the long-term safety and efficacy of darbepoetin alfa for chemotherapy-induced anemia in patients with advanced NSCLC. J Thorac Oncol. 2020, 15:190-202. 10.1016/j.jtho.2019.10.005

19. Gupta S, Singh PK, Bisth SS, et al.: Role of recombinant human erythropoietin in patients of advanced cervical cancer treated "by chemoradiotherapy". Cancer Biol Ther. 2009, 8:13-7. 10.4161/cbt.8.1.7089

20. Hernandez E, Ganly P, Charu V, Dibenedetto J, Tomita D, Lillie T, Taylor K: Randomized, double-blind, placebo-controlled trial of every-3-week darbepoetin alfa 300 micrograms for treatment of chemotherapyinduced anemia. Curr Med Res Opin. 2009, 25:2109-20. 10.1185/03007990903084164

21. Hoskin PJ, Robinson M, Slevin N, Morgan D, Harrington K, Gaffney C: Effect of epoetin alfa on survival and cancer treatment-related anemia and fatigue in patients receiving radical radiotherapy with curative intent for head and neck cancer. J Clin Oncol. 2009, 27:5751-6. 10.1200/JCO.2009.22.3693

22. Leyland-Jones B, Bondarenko I, Nemsadze G, et al.: A randomized, open-label, multicenter, phase III study of epoetin alfa versus best standard of care in anemic patients with metastatic breast cancer receiving standard chemotherapy. J Clin Oncol. 2016, 34:1197-207. 10.1200/JCO.2015.63.5649

23. Pirker R, Ramlau RA, Schuette W, Zatloukal P, Ferreira I, Lillie T, Vansteenkiste JF: Safety and efficacy of darbepoetin alpha in previously untreated extensive-stage small-cell lung cancer treated with platinum plus etoposide. J Clin Oncol. 2008, 26:2342-9. 10.1200/JCO.2007.15.0748

24. Platzbecker U, Symeonidis A, Oliva EN, et al.: A phase 3 randomized placebo-controlled trial of darbepoetin alfa in patients with anemia and lower-risk myelodysplastic syndromes. Leukemia. 2017, 31:1944-50. 10.1038/leu.2017.192

25. Pronzato P, Cortesi E, van der Rijt CC, et al.: Epoetin alfa improves anemia and anemia-related, patient- 
reported outcomes in patients with breast cancer receiving myelotoxic chemotherapy: results of a European, multicenter, randomized, controlled trial. Oncologist. 2010, 15:935-43.

10.1634/theoncologist.2009-0279

26. Ray-Coquard I, Dussart S, Goillot C, et al.: A risk model for severe anemia to select cancer patients for primary prophylaxis with epoetin alpha: a prospective randomized controlled trial of the ELYPSE study group. Ann Oncol. 2009, 20:1105-12. 10.1093/annonc/mdn750

27. Smith RE Jr, Aapro MS, Ludwig H, et al.: Darbepoetin alpha for the treatment of anemia in patients with active cancer not receiving chemotherapy or radiotherapy: results of a phase III, multicenter, randomized, double-blind, placebo-controlled study. J Clin Oncol. 2008, 26:1040-50. 10.1200/JCO.2007.14.2885

28. Tsuboi M, Ezaki K, Tobinai K, Ohashi Y, Saijo N: Weekly administration of epoetin beta for chemotherapyinduced anemia in cancer patients: results of a multicenter, phase III, randomized, double-blind, placebocontrolled study. Jpn J Clin Oncol. 2009, 39:163-8. 10.1093/jico/hyn151

29. Untch M, von Minckwitz G, Konecny GE, et al.: PREPARE trial: a randomized phase III trial comparing preoperative, dose-dense, dose-intensified chemotherapy with epirubicin, paclitaxel, and CMF versus a standard-dosed epirubicin-cyclophosphamide followed by paclitaxel with or without darbepoetin alfa in primary breast cancer--outcome on prognosis. Ann Oncol. 2011, 22:1999-2006. 10.1093/annonc/mdq713

30. Weiss G, Goodnough LT: Anemia of chronic disease. N Engl J Med. 2005, 352:1011-23. 10.1056/NEJMra041809

31. Adamson JW: The anemia of inflammation/malignancy: mechanisms and management . Hematology Am Soc Hematol Educ Program. 2008, 159-65. 10.1182/asheducation-2008.1.159

32. Jelkmann W: Proinflammatory cytokines lowering erythropoietin production. J Interferon Cytokine Res. 1998, 18:555-9. 10.1089/jir.1998.18.555

33. Spivak JL: The blood in systemic disorders . Lancet. 2000, 355:1707-12. 10.1016/S0140-6736(00)02249-2

34. Ganz T, Nemeth E: Hepcidin and disorders of iron metabolism. Annu Rev Med. 2011, 62:347-60. 10.1146/annurev-med-050109-142444

35. Anemia. (2021). Accessed: May 24, 2021: https://www.cancer.net/coping-with-cancer/physical-emotionaland-social-effects-cancer/managing-physical-side-effects...

36. Groopman JE, Itri LM: Chemotherapy-induced anemia in adults: incidence and treatment . J Natl Cancer Inst. 1999, 91:1616-34. 10.1093/jnci/91.19.1616

37. Koshikawa N, Takenaga K: Hypoxia-regulated expression of attenuated diphtheria toxin A fused with hypoxia-inducible factor-1 alpha oxygen-dependent degradation domain preferentially induces apoptosis of hypoxic cells in solid tumor. Cancer Res. 2005, 65:11622-30. 10.1158/0008-5472.CAN-05-0111

38. Dunst J: The use of epoetin alfa to increase and maintain hemoglobin levels during radiotherapy . Semin Oncol. 2001, 28:42-8. 10.1016/s0093-7754(01)90212-x

39. Fatalities reported to the FDA following blood collection and transfusion: annual summary FY2017 . (2017). Accessed: May 24, 2021: https://www.fda.gov/media/124796/download. 